\title{
New Challenges and Opportunities for International Research Collaborations on a More Level Playing Field
}

\author{
Rodolfo H. Torres \\ University Distinguished Professor of Mathematics \\ University of Kansas
}

frequently cited quote from Thom as Friedman reads "When I was growing up, my parents
told me, 'Finish your dinner. People in China and India are sta rving.' I tell my daughters, 'Finish
your homework. People in India and China are starving for your job.'" The world in which we live has drastically changed in some regards and in particular in what respects to science and technology. We do have new international partners and competitors in these areas and the way in which we interact with them is going through drastic transformations. The U.S. leadership in research and development $(R \& D)$ is being challenged, but at the same time new doors for international collaborations have been opened.

More than a decade ago T. Friedman singled out in his celebrated book, "The World is Flat: A brief history of the twentyfirst century"[1], ten "flatteners" responsible for leveling the playing field in terms of commerce and the global economy. These still apply today in a certain sense to or have found a parallel version in international research collaborations with updated meaning. Namely:

- Collapse of the Berlin wall $\rightarrow$ we have experienced the collapse of "the Chinese wall" too, meaning Chinese students and scientists can freely leave their country now and so can foreigners visit China without much restrictions.

- Nestcape $\rightarrow$ of course many new web browsers exist now and, in many countries (though not all), there is "free" access to the internet.

- Workflow software $\rightarrow$ research tools like Dropbox, Google Drive, etc., have become the norm to share collaboration materials.

- Uploading $\rightarrow$ digital repository of articles and scholarly work have proliferated within discipline specific areas (e.g. arXiv.com), universities (e.g. KU Scholar Works), and the government (PubMed Central).

- Outsourcing $\rightarrow$ collaborative research is distributed among scientists in countries around the world (e.g. CERN - European Organization for Nuclear Research or the Human Genome Project). 
- Offshoring $\rightarrow \quad$ American universities continue to open campuses in other countries.

- Supply-chaining $\rightarrow$ like in Friedman's reference to companies using technology to improve distribution and shipping, technology is changing too the way we conduct research.

- Insourcing $\rightarrow$ recruiting and hiring of foreign graduate students and postdocs is fundamental for U.S. universities to carry out their educational and research programs.

- Informing $\rightarrow$ Google and Wikipedia have of course given easy access to a lot of information including advanced scientific and scholarly topics.

- "The steroids" $\rightarrow$ digital mobile devices and now "the cloud" not only revolutionized business and the financial world, but also the way we communicate and storage research information and data.

These "flatteners" together with the investment in science and technology in many emerging economies have indeed made the playing field in R\&D morelevel or at least opened up opportunities for countries not traditionally leading the world scientific research enterprise. We will explore in the rest of this note some of these aspects, providing some examples, data, and metrics.

Two Successful Examples of Open Access and International Collaboration

Numerous ongoing initiatives have had a tremendous impact in scientific research and continue to represent great opportunities for international collaborations. Let's look at two specific examples: the arXiv and the CMS collaboration at CERN.

The arXiv is an open access digital repository hosted by Cornell University Library funded by Cornell University, the Simons Foundation, and member institutions. As of the writing of this article it provides ${ }^{[2]}$ "open access to 1,474,421 e-prints in Physics, Mathematics, Computer Science, Quantitative Biology, Quantitative Finance, Statistics, Electrical Engineering and Systems Science, and Economics". The arXiv was created in 1991 and the total number of articles downloaded from the site through November 2018 exceeded 1.2 billon ${ }^{[3]}$. The following table ${ }^{[4]}$ of the fifteen heaviest user institutions in 2016 is evidence of the international aspect of arXiv. 


\begin{tabular}{|c|c|c|}
\hline & $\begin{array}{l}\text { Institutional } \\
\text { domain }\end{array}$ & $\begin{array}{l}\text { Number of } \\
\text { article } \\
\text { downloads }\end{array}$ \\
\hline 1 & cern.ch & 462,283 \\
\hline 2 & u-tokyo.ac.jp & 400,296 \\
\hline 3 & mpg.de $\left(^{*}\right)$ & 393,252 \\
\hline 4 & cam.ac.uk & 328,921 \\
\hline 5 & mit.edu & 313,570 \\
\hline 6 & berkeley.edu & 284,317 \\
\hline 7 & ethz.ch & 247331 \\
\hline 8 & princeton.edu & 233,363 \\
\hline 9 & kyoto-u.ac.jp & 230,047 \\
\hline 10 & ox.ac.uk & 228,319 \\
\hline 11 & columbia.edu & 183,097 \\
\hline 12 & ic.ac.uk & 165,614 \\
\hline 13 & caltech.edu & 161,805 \\
\hline 14 & in2p3.fr & 161,534 \\
\hline 15 & nus.edu.sg & 157,073 \\
\hline
\end{tabular}

* mpg.de includes downloads from several institutions in Germany.
This free repository has made available at the click of a mouse up-todate research pre-publications to the whole world, exponentially accelerating the sharing of knowledge and new discoveries in the disciplines covered by arXiv.

The CMS Collaboration operates and collects data from the Compact Muon Solenoid particle detectors at the Large Hadron Collider (LHC) in CERN (Conseil Européen pour la Recherche Nucléaire). One of the largest international research collaborations ever, as of October 2016 CMS involves ${ }^{[5]}$ 2885 physicists (of which 922 are students), 995 engineers, and 279 technicians in 198 institutes across 45 countries and regions in 6 continents. The LHC is the largest scientific instrument in the world.

The remarkable achievements of this project, including the discovery of the Higgs boson (a new elementary particle with fascinating properties) are evidence of the need for international collaborations for the most ambitious and complicated experiments in science. At the same time, the collaboration has allowed for the participation of scientists from some countries around the world which would have never had resources to conduct such high-tech research otherwise. This has resulted in access to human capital and brilliant minds worldwide while in turn also contributed to the scientific progress of less developed countries.

Some Worldwide Metrics and

\section{Trends}

While the previous examples speak of open and embracing inter- 
national collaborations, competition among countries in scientific research also exists and has been escalating over the years. Moreover, while keeping the lead in many areas related to science and technology, the U.S. has started to lag or is predicted to soon lag in some commonly used metrics of research activity and productivity when compared to new international competitors, in particular China.

The National Science Board (NSB) Science and Engineering Indicators (Indicators), provides a wealth of information about science and engineering and research and development in the U.S. and the world. The Indicators are a congressionally mandated report which is intended to be factual and policy neutral. According to the most recent report ${ }^{[6]}$,

"The United States holds a preeminent position in SEE in the world, derived in large part from its long history of public and private investment in SEE research and development and education. Investment in RED, science, technology, and education correlate strongly with economic growth and with the development of a safe, healthy, and well-educated society.

Many other nations, recognizing the economic and social benefits of such investment, have increased their RED and education spending. These trends are by now well-established. SEE capabilities, until recently located mainly in the United States, Western Europe, and Japan, have now spread to other parts of the world, notably to China and other Southeast Asian economies that are heavily investing to build their scientific and technological capabilities."

In the views of Maria Zuber, NSB Chair and Vice President for Research at the Massachusetts Institute of Technology ${ }^{[7]}$, "This year's report shows a trend that the U.S. still leads by many SET measures, but that our lead is decreasing in certain areas that are important to our country," adding "That trend raises concerns about impacts on our economy and workforce, and has implications for our national security." We include here some key graphs, plots, and information from the 2018 Digest $^{[7]}$ version of the report.

In the plots in Figure $1^{[8, \mathrm{p} .5]}$ we see several aspects of R\&D at the global level which show how much Asia in general and China in particular have become much bigger players. Plot A shows that worldwide expenditures in $R \& D$ have grown almost linearly from around $\$ 700$ billon in the year 2000 to almost \$2 trillion in the year 2015. Although in all the countries or regions with the largest R\&D expenditures such expenditures continue to grow in a linear fashion too, we see in Plot C that China's expenditures have not followed such a trend and speeded up to become second only to the U.S.. At the same time the share of worldwide $R \& D$ during the same period has changed substantially: Plot B shows that, while North America had the largest share in 2000, Asia has the largest one in 2015. Plots D and E also show how the biggest growth in $R \& D$ has geographically moved to Asia. China, South Korea, and India were the countries with the largest annual average growth (Figure E) and together with other Asian nations they accounted for 
about $50 \%$ of the contributions to worldwide R\&D growth (Figure D). China alone accounted for $31 \%$ of such worldwide contributions. However, in R\&D intensity ( $R \& D$ expenditures as a percentage of GDP), as shown in Plot F, China had not reached as of 2015 the level of the US. On the other hand, South Korea surpassed the US in R\&D intensity after 2009. Following linear regression projections, it is predicted that China would surpass the US this year in terms of gross expenditures in R\&D and in 2020 it would do so in terms of R\&D intensity.

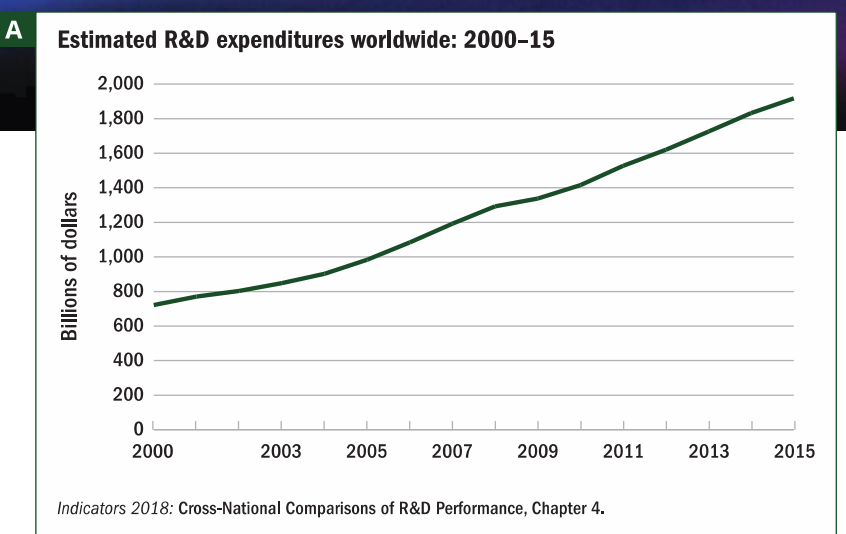

Domestic R\&D expenditures, by selected country: 2000-15

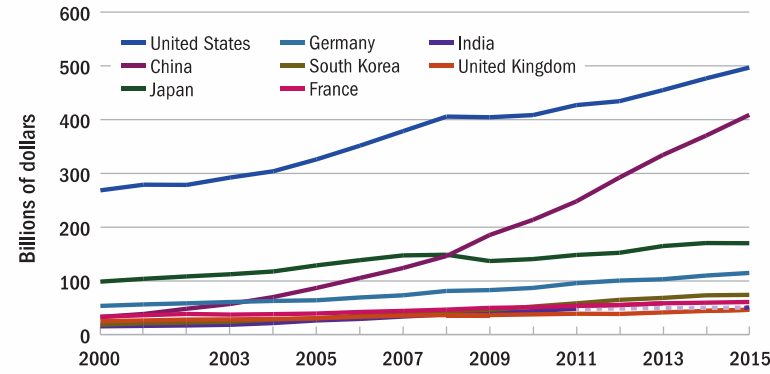

NOTES: Data are not available for all countries for all years. Dotted line connects across missing values. Indicators 2018: Cross-National Comparisons of R\&D Performance, Chapter 4.

Average annual growth in domestic R\&D expenditures, by selected region, country, or economy: 2000-15

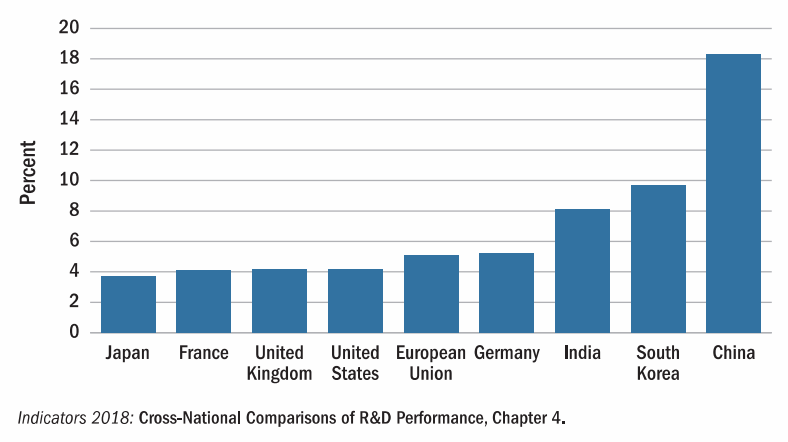

Regional share of worldwide R\&D expenditures: 2000 and 2015

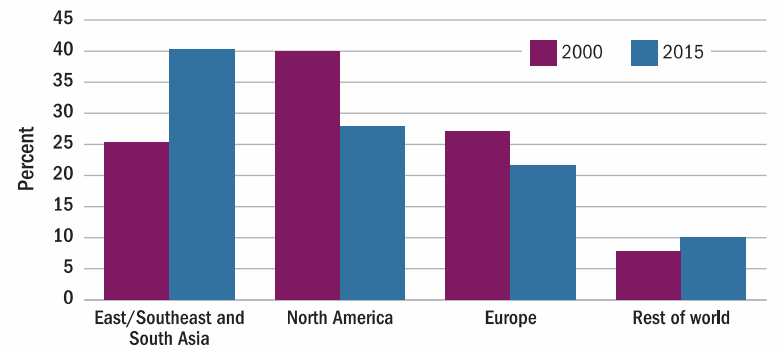

NOTE: East/Southeast and South Asia includes China, Taiwan, Japan, South Korea, Singapore, Malaysia Thailand, Indonesia, Philippines, Vietnam, India, Pakistan, Nepal, and Sri Lanka. Indicators 2018: Cross-National Comparisons of R\&D Performance, Chapter 4.

Contributions to growth of worldwide R\&D expenditures, by selected region, country, or economy: 2000-15

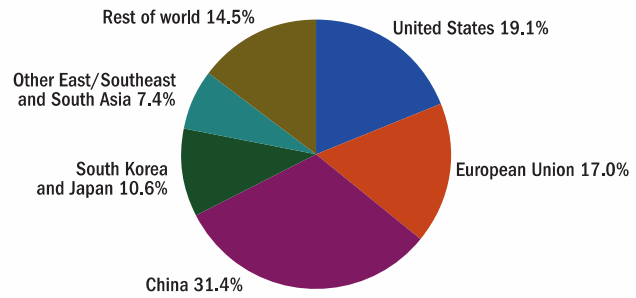

NOTE: Other East/Southeast and South Asia includes Taiwan, Singapore, Malaysia, Thailand, Indonesia, Philippines, Vietnam, India, Pakistan, Nepal, and Sri Lanka.

Indicators 2018: Cross-National Comparisons of R\&D Performance, Chapter 4.

R\&D intensity, by selected region, country, or economy: 2000-15

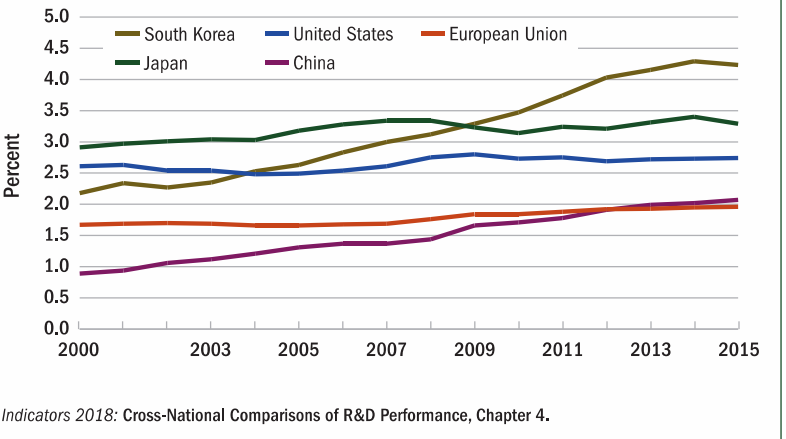

Figure 1 - Science and Engineering Indicators 2018 Digest www.nsf.gov/statistics/digest/ 
Several metrics related to science and technology capabilities are plotted in in Figure $2^{[8, p .9]}$. Of particular note is again the fact that China has surpassed already the US in terms of S\&E published research articles (Plot A). The rapid growth of China in other metrics is also reflected in the other plots of the figure.
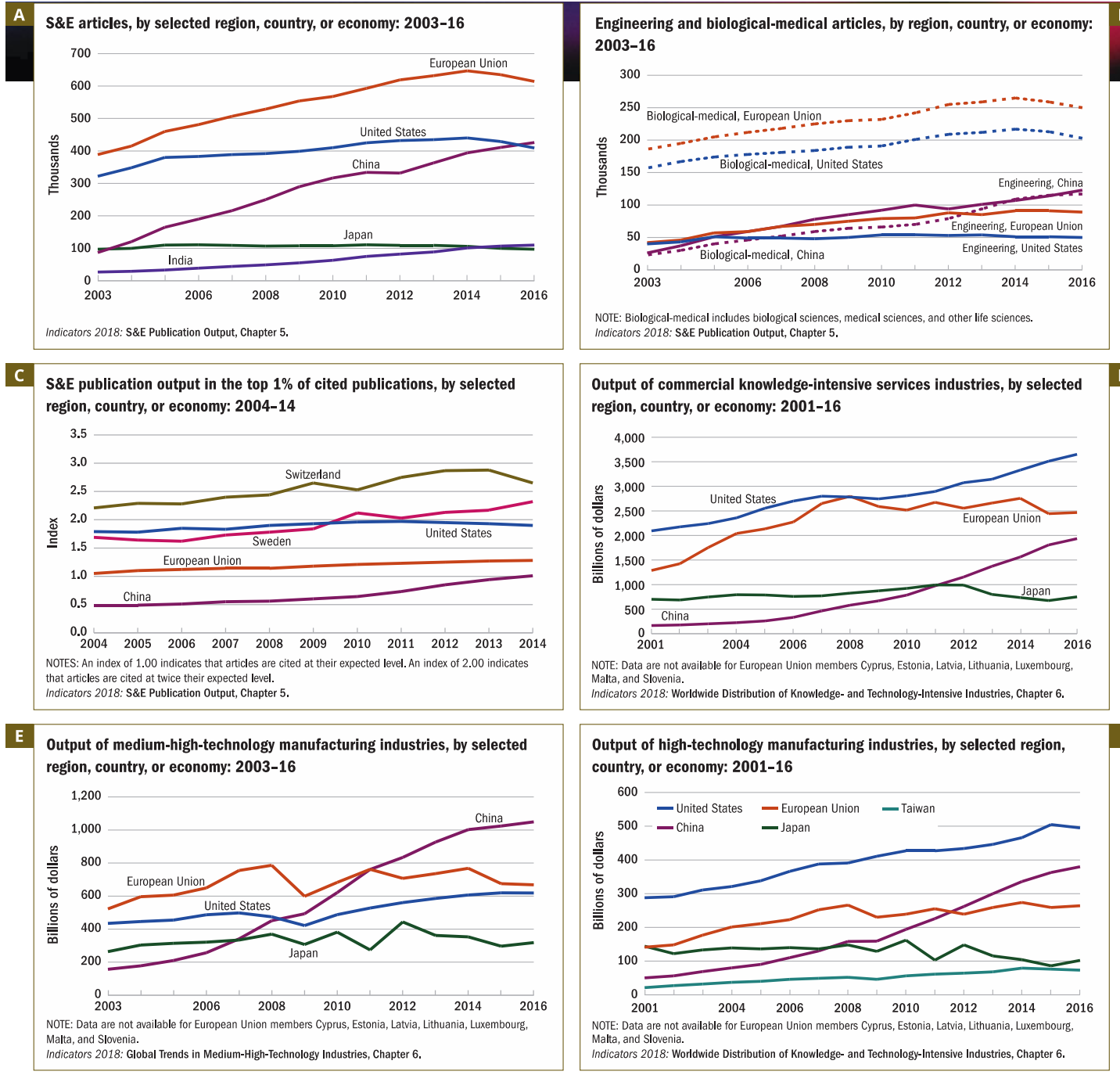

Output of commercial knowledge-intensive services industries, by selected region, country, or economy: 2001-16

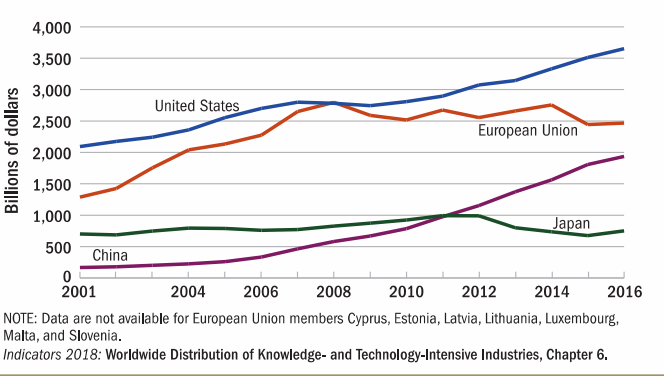

Output of high-technology manufacturing industries, by selected region, country, or economy: 2001-16

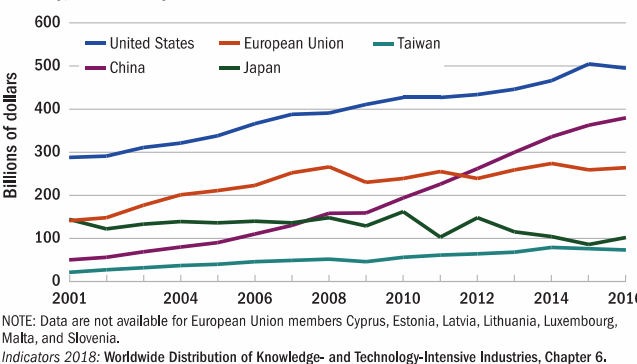

Figure 2 - Science and Engineering Indicators 2018 Digest www.nsf.gov/statistics/digest/

Global S\&E education follows similar trends in China and we see in Figure $3[8$, p.13] its rapid growth regarding bachelor's degrees awarded in S\&E fields. For example, in 2014 the number of degrees awarded in China more than double the number in the U.S. 


\section{Bachelor's degree awards in S\&E fields, by selected region, country, or economy: 2000-14}

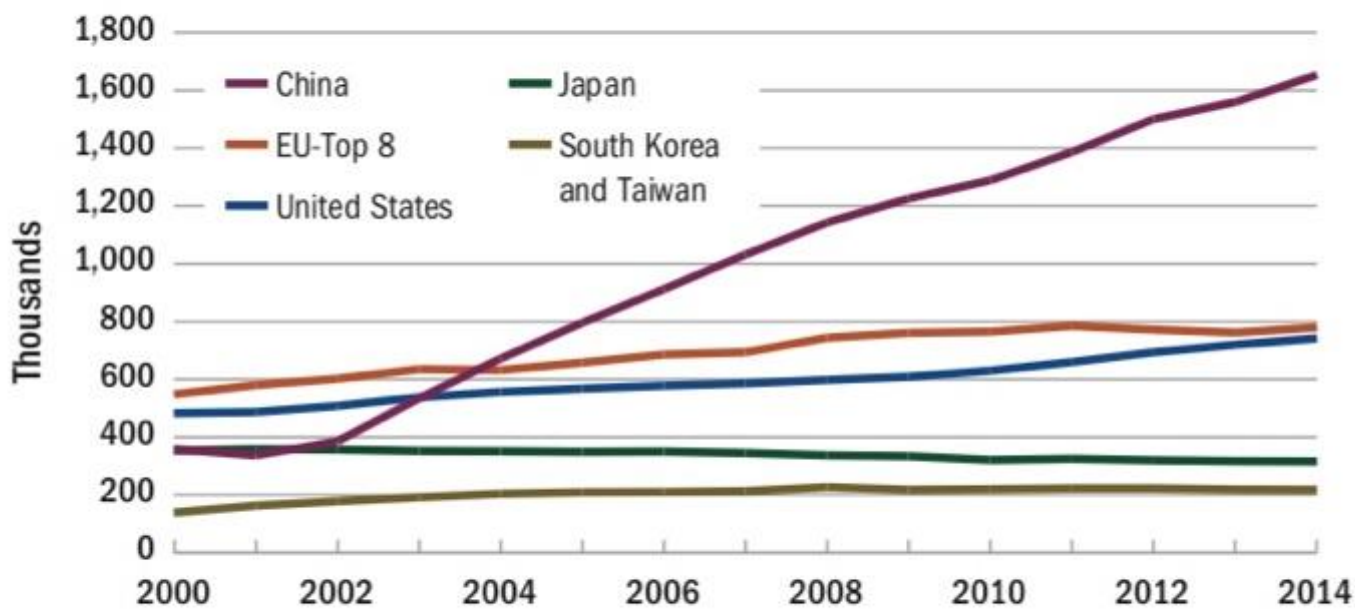

NOTE: EU-Top 8 is the eight European Union countries with the most bachelor's degree awards in 2014: UK, Germany, France, Poland, Italy, Spain, Romania, and the Netherlands.

Indicators 2018: First University Degrees in S\&E Fields, Chapter 2.

Figure 3 - Science and Engineering In dicators 2018 Digest www.nsf.gov/statistics/digest/

The U.S. still produced more PhDs in S\&E fields than China as of 2014, but it did so by relying on temporary U.S. visa holders who accounted for more than a third of the recipients of those degrees. See Figure $4^{[8, p, 13]}$.

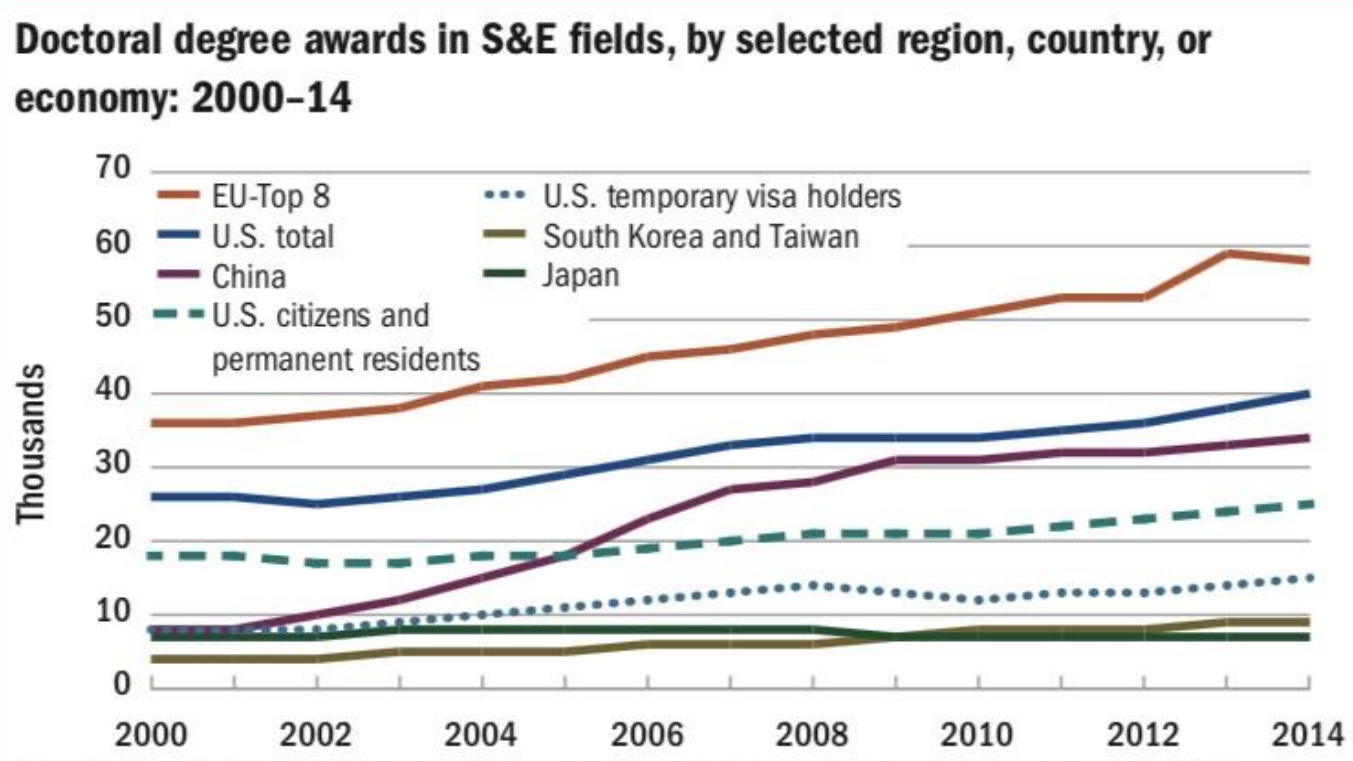

NOTE: EU-Top 8 is the eight European Union countries with the most doctoral degree awards in 2014: Germany, UK, France, Spain, Italy, Portugal, Sweden, and Romania. Indicators 2018: International Comparison of S\&E Doctoral Degrees, Chapter 2.

Figure 4 - Science and Engineering Indicators 2018 Digest www.nsf.gov/statistics/digest/ 
Additional data from the Indicators ${ }^{[9]}$ related to international students is quite revealing too. We extract the following points:

- Since 2008, enrollment of international students in SEE fields has been rising, while graduate enrollment of U.S. citizens and permanent residents has declined overall.

- In 2015, international students accounted for $36 \%$ of SEE graduate students, compared with $26 \%$ in 2008.

- In 2015, international students earned more than half of the doctoral degrees awarded in engineering, economics, computer sciences, and mathematics and statistics.

- In fall 2017,69\% of the international $S \mathcal{E E}$ graduate students in the United States came from China and India, similar to prior years.

These data clearly show how much the U.S. relies on foreign students to carry on its education and research programs in S\&E.

Increasing Funding Opportunities in Other Countries and Balancing Open Access with Technology Protection and National Security

Not only Europe and Japan continue to invest in collaborative projects but also new opportunities for research funding are being developed in Brazil, China, India and other countries. While the investments of these countries in $R \& D$ increase their competitiveness and their share of the worldwide research enterprise, they also provide opportunities for U.S. scientists and students. An increasing number of international conferences in S\&E take place outside the U.S. and are substantially funded by governmental and private organization in the host countries. This provides resources for U.S. scientists to visit those countries and establish new collaborations. At the same time, it is more and more common to find at U.S. institutions international students, postdoctoral fellows, and scientists participating in long stays financially supported by their countries of origin. These international exchanges happen then without financial investments from U.S. resources and hence are very much welcome by universities.

The open access and free exchange of knowledge is fully supported by the Association of American Universities (AAU) and the Association of Public and Land-grant Universities (APLU). In fact, the recent AAU-APLU Public Access Working Group Report and Recommendations ${ }^{[10]}$ "summarizes actions that universities and federal agencies can take to advance public access to data in a viable and sustainable way." In particular, the following broad goals are supported by the report:

- Providing public access to research data in the most useful ways to society;

- Minimizing the administrative burden on agencies, universities, and researchers;

- Allowing exceptions for prizacy, security, and intellectual property (IP) concerns;

- Prioritizing data quality and its rigorous evaluation as a foundation in preparing, documenting, and releasing data;

- Balancing the substantial costs of data access against the benefits of access;

- Recognizing that data types and accessibility needs vary across disciplines, requiring a flexible approach; and 
- Considering the community of interest and duration of usefulness for the data in question and making retention and access requirements clear.

Having open access data in the U.S. in a format easily reachable through internet tools, means also that data and research would become completely open to the whole world. Because of the diversity of activities and countries involved in international exchanges, it is becoming an increasing challenge for U.S. universities to balance openness with the federal export control regulations. As stated in the report Dual Use Research of Concern in the Life Sciences ${ }^{[1, C h}$. 3] from the National Academies, the National Security Decision Directive 189 (NSDD-189) states ${ }^{[12]}$ : “. .. to the maximum extent possible, the products of fundamental research remain unrestricted." However, when more applied, dual-use, or specific areas of research are involved there are federal regulations and agencies that control exports of research and technology. In particular,

- The U.S. Department of Commerce's Bureau of Industry and Security (BIS) administers the Export Administration Regulations (EAR) that govern the export of commercial and dual-use goods;

- The U.S. Department of State's Directorate of Defense Trade Controls (DDTC), administers the International Traffic and Arms Regulations (ITAR) that govern the export of defense articles, defense services and technical data;

- The U.S. Department of the Treasury's Office of Foreign Assets Control (OFAC) administers country-specific economic and trade sanctions that often include restrictions exports to targeted countries.

Unfortunately, it is not uncommon to read in the news that individuals and/or institutions get fined or legally prosecuted for violations of export control regulations. A recent White House Office of Trade and Manufacturing Policy report [13] points to this data: "the annual cost to the U.S. economy continues to exceed $\$ 225$ billion in counterfeit goods, pirated software, and theft of trade secrets and could be as high as $\$ 600$ billion". While some defense and commerce related research and the resulting technologies are clearly identifiable for export control restrictions, it is more difficult to do so with scientific discoveries in areas of fundamental research. Universities need to better train their faculty and students regarding export control regulations to avoid sometimes unintentional law violations.

\section{Conclusions}

The world has indeed flattened in terms of economic development and hence, not surprisingly, also in terms of scientific research and technology. While the U.S. has a head start in many areas related to $R \& D$, other nations are catching up and have serious ambitions to become leaders in the research arena. The U.S. has traditionally opened its doors to the best minds, both students and scientists, from around the world and still relies on foreign students to fill its doctoral programs in S\&E. New opportunities exist for international collaborations and some have already proven to be very productive. The use of modern technology and means of communication has facilitated such collaborations. Yet there are concerns 
about what research and technologies should be protected and how to maintain a balance with the emerging philosophy of global open access to data and research. Export control is a difficult compliance issue for many universities and more training, education and discussions about the topic are needed.

In the words of Tom Wang, chief international officer and director of the AAAS Center for Science Diplomacy, American Association for the Advancement of Science (AAAS) [14], "Ultimately, the United States has always recognized that it needs and benefits from more international openness. To maintain global leadership in science and technology in the 21st century, the United States must remain a champion of engagement and cooperation, not isolation". American universities, the organizations that group them, and government agencies should continue to work together to find the right balance protecting the U.S. national interests while allowing for theimportant and mutually beneficial international collaborations that our universities conduct.

\section{References}

[1] The World Is Flat: A Brief History of the Twenty-First Century, Thomas L.

Friedman, New York, NY, Farrar, Straus and Giroux, 2005.

[2] arXiv.org, Cornell University Library, https://arxiv.org, accessed 08 Dec. 2018.

[3] arXiv.org>stats, Cornell University Library,

https://arxiv.org/stats/monthly downloads, accessed 08 Dec. 2018.

[4] 2016 Institutional arXiv Usage Data, Cornell University Library, https://arxiv.org/help/support/2016_usage, accessed 08 Dec. 2018.

[5] People Statistics, The CMS Experiment at CERN, https://cms.cern/collaboration/people-statistics, accessed 08 Dec. 2018.

[6] 2018 Digest, Science \& Engineering Indicators, National Science Board, National Science Foundation, https://www.nsf.gov/statistics/2018/nsb20181/digest/sections/introduction, accessed 08 Dec. 2018.

[7] State of US science enterprise report shows US leads in S\&E as China rapidly advances, National Science Foundation, https://nsf.gov/news/news summ.jsp?cntn id=244271, accessed 08 Dec. 2018.

[8] Science \& Engineering Indicators, 2018 Digest, National Science Board, January 2018, NSB-2018-2.

[9] Science \& Engineering Indicators 2018, Chapter 2, National Science Board, National Science Foundation, https://www.nsf.gov/statistics/2018/nsb20181/report/sections/higher-educationin-science-and-engineering/highlights, accessed 08 Dec. 2018.

[10] AAU-APLU Public Access Working Group Report and Recommendations, November 29, 2017, https://www.aau.edu/sites/default/files/AAU-Files/KeyIssues/Intellectual-Property/Public-Open-Access/AAU-APLU-Public-AccessWorking-Group-Report.pdf, accessed 08 Dec. 2018.

[11] Dual Use Research of Concern in the Life Sciences, Current Issues and Controversies (2017), The National Academies of Sciences, Engineering, and 
Medicine, https://www.nap.edu/catalog/24761/dual-use-research-of-concern-inthe-life-sciences-current, accessed 08 Dec. 2018.

[12] National Policy on the Transfer of Scientific, Technical and Engineering Information, National Security Decision Directives (NSDD), https://fas.org/irp/offdocs/nsdd/nsdd-189.htm, accessed 08 Dec. 2018.

[13] How China's Economic Aggression Threatens the Technologies and Intellectual Property of the United States and the World, White House Office of Trade and Manufacturing Policy June 2018, https://www.whitehouse.gov/wpcontent/uploads/2018/06/FINAL-China-Technology-Report-6.18.18-PDF.pdf, accessed 08 Dec. 2018.

[14] https://twitter.com/aaas/status/1013771983534870529 